\title{
Koebner phenomenon in a patient with hypertrophic chronic cutaneous lupus erythematosus
}

\author{
Marta Dobrzyńska1, Adriana Polańska², Monika Bowszyc-Dmochowska ${ }^{3}$, Dorota Jenerowicz ${ }^{1}$, Sebastian Lisowski ${ }^{1}$, \\ Magdalena Czarnecka-Operacz ${ }^{1}$, Zygmunt Adamski ${ }^{1}$, Aleksandra Dańczak-Pazdrowska ${ }^{1}$
}

'Department of Dermatology, Poznan University of Medical Sciences, Poznan, Poland

${ }^{2}$ Department of Dermatology and Venerology, Poznan University of Medical Sciences, Poznan, Poland

${ }^{3}$ Cutaneous Histopathology and Immunopathology Section, Department of Dermatology, Poznan University of Medical Sciences,

Poznan, Poland

Adv Dermatol Allergol 2021; XXXVIII (1): 163-166

DOI: https://doi.org/10.5114/ada.2021.102937

Koebner phenomenon was described for the first time by Heinrich Koebner in 1876. Development of new lesions as a consequence of cutaneous trauma was observed in uninvolved skin of the patient with psoriasis. Nowadays it is known that the Koebner phenomenon (also called isomorphic response) can be present in a variety of dermatoses including lichen planus, vitiligo, erythema multiforme, Darier disease and lichen striatus [1-3]. There are very few literature reports about the Koebner phenomenon in systemic or cutaneous lupus erythematosus (CLE) [4-9].

The aim of the study is to present the case of the Koebner phenomenon as a consequence of scratching in a patient with hypertrophic disseminated chronic CLE (CCLE).

A 53-year-old female patient was admitted to the Department of Dermatology due to multiple hyperkeratotic, erythematous lesions located on the scalp, face, upper part of the trunk and upper extremities. The patient was diagnosed with discoid lupus erythematosus (DLE) in 2010. Past treatment involved moderate and high potency topical steroids and $250 \mathrm{mg}$ of chloroquine orally for several years. Recently she received oral methylprednisolone, but despite increasing the daily dose from $4 \mathrm{mg}$ up to $16 \mathrm{mg}$, the disease was progressing continuously.

Physical examination on the day of admission revealed linear atrophic scars with peripheral inflammation within the skin of the trunk. Arrangement of the lesions suggested repetitive excoriations (Figure 1 A). Moreover numerous erythematous and hyperkeratotic, nodular lesions were found on the trunk and upper extremities. The most severe and painful skin lesions with the verrucous surface, fissures, recurrent bleeding and features of su- perinfection were located on the hands (Figure 1 B). Scarring alopecia on the scalp was present. Mucous membranes were not affected. The patient complained about pruritus and admitted to scratching. She also reported paraesthesia of the fingers.

Complete blood count was normal, except thrombocytosis $\left(445 \times 10^{3} / \mu \mathrm{l}\right.$; normal range: $\left.400 \times 10^{3} / \mu \mathrm{l}\right)$. Laboratory testing showed an increased erythrocyte sedimentation rate $(77 \mathrm{~mm} / \mathrm{h}$; normal range: $0-12 \mathrm{~mm} / \mathrm{h})$ and C reactive protein (14.8 $\mathrm{mg} / \mathrm{l}$; normal range: $0-5 \mathrm{mg} / \mathrm{l})$. C3 complement was decreased $(0.083 \mathrm{~g} / \mathrm{l}$; normal range: 0.1-0.4). Autoantibody screening revealed positive antinuclear antibodies (ANA) with a titre of $1: 640$, with no particular subtype found. The following tests were negative: lupus anticoagulant, anticardiolipin antibodies IgM, IgG, anti-2-glycoprotein IgM, IgG, rapid plasma reagin. 24-urine collection was done but no significant proteinuria was found (0.2 g/day; normal range: $0.15 \mathrm{~g} /$ day).

Radiological imaging: chest $X$-ray and abdominal ultrasound showed no significant abnormalities.

Punch biopsy was taken for microbiological examination to exclude tuberculosis cutis. Direct preparation and culture revealed no mycobacteria. Additionally the real-time PCR test showed no DNA of Mycobacterium tuberculosis. QuantiFERON TB Gold test also was negative.

Another punch biopsy was taken for the histopathological examination, which confirmed the diagnosis of hypertrophic CCLE. The characteristic features were: epidermal thickening with the pseudoepitheliomatous hyperplasia, vacuolation and necrosis of basal keratinocytes, with the presence of subepidermal fissures and quite abundant, diffused lymphocytic and histiocytic infiltrates beneath the epidermis.

Address for correspondence: Marta Dobrzyńska MD, Department of Dermatology, Heliodor Swiecicki University Hospital, Poznan University of Medical Sciences, 49 Przybyszewskiego St, 60-355 Poznan, Poland, phone: +48 505972811 , e-mail: m.a.dobrzynska@gmail.com Received: 22.11.2019, accepted: 27.11.2019. 

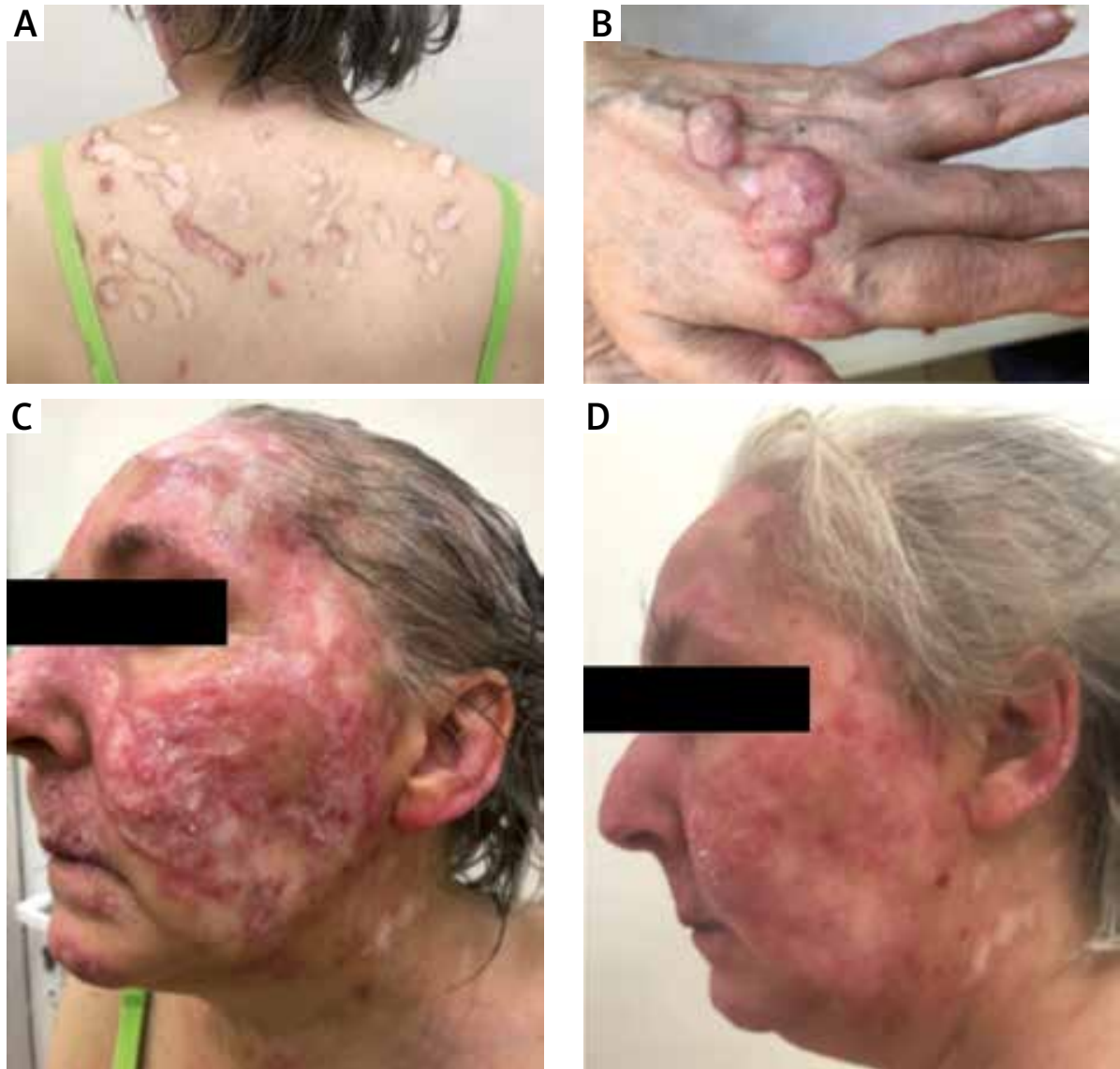

Figure 1. A - Koebner phenomenon - linear atrophic scars with peripheral inflammation on the trunk, B - hypertrophic, nodular lesions with the verrucous surface on the dorsal hands characteristic of hypertrophic CCLE, C - infiltration and erythematous lesions on the face on the day of admission, $\mathbf{D}$ - flattening and partial regression of skin lesions after 6-week treatment

The treatment with chloroquine in the dose of $250 \mathrm{mg}$ and acitretin of $25 \mathrm{mg}$ was introduced, along with topical steroids. The previous methylprednisolone treatment has been maintained, but with a gradually reduced dose down to $4 \mathrm{mg}$ daily. The follow-up examination was performed after 6 weeks of treatment. Marked improvement of the clinical condition was visible with the flattening and partial regression of skin lesions as a result (Figure 2). According to the patient also the itching sensation has been re-

Table 1. Dermatoses with Koebner phenomenon

\begin{tabular}{l}
\hline Psoriasis \\
\hline Lichen planus \\
\hline Vitiligo \\
\hline Erythema multiforme \\
\hline Darier's disease \\
\hline Lichen striatus \\
\hline Lichen sclerosus \\
\hline Warts
\end{tabular}

duced. As the tolerability and no adverse effects appeared, the treatment has been continued.

CLE. It is characterized by irregular epidermal hyperplasia and hyperkeratosis. In this case the differential diagnosis included tuberculosis cutis, keratosis lichenoides chronica and hypertrophic actinic keratosis. Some of the lesions resembled disseminated warts. Also excluding the squamous cell carcinomas and multiple keratoacanthoma seems to be significant.

Koebner phenomenon is a well-known symptom which can be present in many dermatoses (Table 1), however it has been rarely described in LE (Table 2).

Pathogenesis of CLE is multifactorial and includes genetics, innate and adaptive immune response and environmental triggers [4]. There are few literature reports about new CLE lesions provoked by cutaneous trauma, UV-exposure [5-7], tattoos [8, 9], heat [10], herpes zoster [11] or nickel contact dermatitis [12]. In the reported case presumably skin lesions were a result of scratching as pruritus is frequently observed in CLE. According to the Multicenter, Multinational Cross-Sectional Study about Prevalence of Pruritus in Cutaneous Lupus Erythematosus, 100\% of patients with hyper- 
Table 2. Koebner phenomenon in LE - review of case reports

\begin{tabular}{|c|c|c|c|c|}
\hline Author & Year & Type of LE & Clinical findings & Triggering factor \\
\hline Ueki & 1994 & $\begin{array}{c}\text { SLE } \\
\text { SCLE } \\
\text { DLE }\end{array}$ & Various isomorphic reactions & $\begin{array}{l}\text { Traumas, scratching, operation scars, } \\
\text { contact dermatitis, pressure from sock } \\
\text { tops, application of liquid nitrogen, } \\
\text { exposure to strong sunlight }\end{array}$ \\
\hline Jolly & 2005 & DLE & Circular, raised lesions superimposed on the tattoo & 1-year-old tattoo \\
\hline Lukacs et al. & 2011 & CLE & $\begin{array}{l}\text { Ears and on the nasal } \\
\text { Tip: centrally atrophic, livid-erythematous, slightly } \\
\text { scaling } \\
\text { Plaques } \\
\text { Right thumb and index } \\
\text { Finger: erythematous fissured patches }\end{array}$ & $\begin{array}{l}\text { Allergic contact dermatitis induced by } \\
\text { nickel }\end{array}$ \\
\hline Berger et al. & 2012 & DLE & $\begin{array}{l}\text { Lower back: large, atrophic, and reticulated plaque with } \\
\text { a hyperpigmented border; } \\
\text { Thumb: well-demarcated, erythematous plaque with } \\
\text { adjacent loss of the medial nail plate on the affected } \\
\text { finger }\end{array}$ & $\begin{array}{l}\text { Chronic heat exposure in patient who } \\
\text { was a baker by profession }\end{array}$ \\
\hline Lee et al. & 2013 & SLE & $\begin{array}{l}\text { Dermatomal band of atrophic, scaly, erythematous } \\
\text { papules and plaques was noted extending from the left } \\
\text { upper } \\
\text { Back to the posterior aspect of the left arm }\end{array}$ & Herpes zoster infection \\
\hline Wang et al. & 2019 & DLE & $\begin{array}{l}\text { Linear formation of small papules and plaques along } \\
\text { tattoos }\end{array}$ & Old tattoos \\
\hline
\end{tabular}

trophic CCLE were complaining about the pruritus. Also the intensity of pruritus in patients with hypertrophic CCLE was the highest among all CLE subtypes [13].

The Systemic Lupus International Collaborating Clinics (SLICC) criteria were used to determine the diagnosis of systemic lupus erythematosus (SLE) [14]. One clinical (CCLE) and two immunologic (ANA and low C3 complement) criteria were fulfilled. Due to neurologic symptoms the patient was referred to the neurologist. Because of the poor compliance (the patient did not deliver results of consultation) neither excluding nor establishing the diagnosis of SLE was possible.

As to date, no drugs have been specifically approved for CLE, however retinoids seem to be particularly useful in cases of hypertrophic forms of CLE. According to current recommendations, the use of acitretin or isotretinoin in a dose of $0.2-1 \mathrm{mg} / \mathrm{kg} /$ day, especially in addition to anti-malarials in the cases of hypertrophic CCLE is advised [14-16]. In this case, results of 6-week treatment showed significant improvement.

In conclusion, the Koebner phenomenon rarely occurs in LE, but can be observed in CLE. It is possible that a common subjective symptom of CLE - pruritus and repetitive scratching could contribute to developing new skin lesions. Antipruritic therapy can be considered in the treatmentresistant patients with CCLE.

\section{Conflict of interest}

The authors declare no conflict of interest.

\section{References}

1. Sagi L, Trau H. The Koebner phenomenon. Clin Dermatol 2011; 29: 231-6.

2. Thappa DM. The isomorphic phenomenon of Koebner. Indian J Dermatol Venereol Leprol 2004; 70: 187-9.

3. Dańczak-Pazdrowska A, Pawlaczyk-Gabriel K, Bowszyc-Dmochowska M, et al. Reverse Köbner response in lichen striatus: the first case described in the literature. Adv Dermatol Allergol 2018; 35: 434-5.

4. Ueki H. Köbner phenomenon in lupus erythematosus. Hautarzt 1994; 45: 154-60.

5. Jolly M. Discoid lupus erythematosus after tattoo: Koebner phenomenon. Arthritis Rheum 2005; 53: 627.

6. Lukacs A, Karpati S, Temesvari E. Nickel-induced Koebner phenomenon in chronic cutaneous lupus erythematosus. J Dtsch Dermatol Ges 2011; 9: 475-6.

7. Berger E, Robinson M, Patel R, et al. Koebner phenomenon to heat in cutaneous (discoid) lupus erythematosus (lupus ab-igne). Dermatol Online J 2012; 18: 17.

8. Lee NY, Daniel AS, Dasher DA, et al. Cutaneous lupus after herpes zoster: isomorphic, isoptic, or both? Pediatr Dermatol 2013; 30: 110-3.

9. Wang RF, Maher M, Chung C, et al. Koebner phenomenon of discoid lupus erythematosus on old tattoos. Lupus 2019; 28: 241-3.

10. Hejazi EZ, Werth VP. Cutaneous lupus erythematosus: an update on pathogenesis diagnosis and treatment. Am J Clin Dermatol 2016; 17: 135-46.

11. Longhi BS, Centeville M, Marini R, et al. Koebner's phenomenon in systemic lupus erythematosus. Rheumatol Int 2012; 32: 1403-5.

12. Ueki H. Koebner phenomenon in lupus erythematosus with special consideration of clinical findings. Autoimmun Rev 2005; 4: 219-23. 
13. Samotij D, Szczęch J, Kushner CJ, et al. Prevalence of pruritus in cutaneous lupus erythematosus: brief report of a multicenter, multinational cross-sectional study. Biomed Res Int 2018; 25: 3491798.

14. Petri M, Orbai AM, Alarcón GS, et al. Derivation and validation of systemic lupus international collaborating clinics classification criteria for systemic lupus erythematosus. Arthritis Rheum 2012; 64: 2677-86.

15. Kuhn A, Aberer E, Bata-Csorgo Z, et al. S2k guideline for treatment of cutaneous lupus erythematosus - guided by the European Dermatology Forum (EDF) in cooperation with the European Academy of Dermatology and Venereology (EADV). J Eur Acad Dermatol Venereol 2017; 31: 389-404.

16. Woźniacka A, Sysa-Jędrzejowska A, Reich A, et al. Cutaneous lupus erythematosus. Diagnostic and therapeutic recommendations of the Polish Dermatological Society. Dermatol Rev 2018; 105: 244-63. 